pulmonary vascular resistance, as in many cases of mitral regurgitation. In this case pulmonary vascular resistance was greatly increased. While this could be due to an effect of fenfluramine on the pulmonary vessels, it might also be explained as a secondary effect of left ventricular failure due to the mild systemic hypertension present. Increased left ventricular end-diastolic pressure to $25 \mathrm{~mm} \mathrm{Hg}$ or more is often accompanied by modest increases in pulmonary vascular resistance (200-300 dyn-s-cm $\left.{ }^{-5}\right){ }^{12}$ In this patient, however, pulmonary vascular resistance was greatly increased (440), with a left ventricular end-diastolic pressure of only $18 \mathrm{~mm} \mathrm{Hg}$. Also, despite effective treatment of the hypertension with a diuretic she again developed symptoms and electrocardiographic evidence of pulmonary hypertension on rechallenge with fenfluramine. This evidence suggests that the reversible component of her pulmonary hypertension was due to fenfluramine.

Fenfluramine is an effective antiobesity agent with mild hypoglycaemic properties. ${ }^{1314}$ Hence, particularly when given to obese diabetics, drug treatment may be recommended for more than six months. Administration for six months produces weight loss in many patients but on drug withdrawal a gain in weight is the rule. ${ }^{15}$ The hazards of prolonged use of fenfluramine remain to be evaluated. Pulmonary hypertension is the most serious to date, and we recommend that patients taking fenfluramine should be advised to report immediately any deterioration in exercise tolerance.

We thank Mrs J Troup and Mrs M Murray for secretarial help. Requests for reprints should be addressed to: Dr J G Douglas, Medical Unit, Eastern General Hospital, Seafield Street, Edinburgh EH6 7LN.

\section{References}

${ }^{1}$ Gagnon MA, Bordileau JW, Tetreault L. Fenfluramine: study of its central action through the effect on sleep. International fournal of Clinical Pharmacology, $1969 ; 1: 74-82$.

2 Steel JM, Briggs $M$. Withdrawal depression in obese patients after fenfluramine treatment. $\mathrm{Br} \mathrm{Med} \mathcal{F} 1972$;iii:26-7.

3 Gurtner HP, Gertsch M, Salzmann C, Sherrer M, Stucki P, Wyss F. Haüfen sich die primär vasculären Formen des chronischen Cor pulmonale ? Schweiz Med Wochenschr 1968;98:1579-89, 1695-707.

4 Follath F, Buckart F, Schweizer W. Drug-induced pulmonary hypertension? $\mathrm{Br}$ Med $\mathcal{F} 1971$; : $265-6$.

5 Barratt-Boyes BG, Wood EH. Cardiac output and related measurements and pressure values in the right heart and associated vessels. $\mathcal{F}$ Lab Clin Med 1958;51:72-90.

${ }^{6}$ Paeprer K. Hypotonie und Appetitzügler. Arztliche Praxis 1970;22:1397.

${ }^{7}$ Fahlen M, Bergmar H, Helder G, Ryden L, Wallentin I, Zettergren L. Phenformin and pulmonary hypertension. Br Heart $\mathcal{f} 1973 ; 35: 824-8$.

${ }^{8}$ Kleiger RE, Boxer M, Ingham RE, Harrison DC. Pulmonary hypertension in patients using oral contraceptives. Chest 1976;69:143-7.

${ }^{9}$ Engelhardt A, Kroneberg G, Stoepel K, Stötzer H. The effects of acute and chronic administration of sympathomimetic substances on the systemic and pulmonary circulation. Proceedings of the European Society for the Study of Drug Toxicity 1970;11:110-7.

10 Prime FJ. Dangers of certain appetite suppressants. Br Med f 1969 ;iii:177.

11 Bourdillon PDV, Oakley CM. Regression of primary pulmonary hypertension. Br Heart $\mathcal{F} 1976 ; 38: 264-70$.

12 Grossman W, Braunwald E. Pulmonary hypertension. In: Braunwald E, ed. Heart disease. Philadelphia: Saunders, 1980:841.

13 Wales JK. The effect of fenfluramine on obese, maturity-onset diabetic patients. Curr Med Res Opin 1979;6, suppl 1:226-35.

14 Turtle JR, Burgess JA. Hypoglycaemic action of fenfluramine in diabetes mellitus. Diabetes 1973;22:858-67.

15 Hudson KD. The anorectic and hypotensive effect of fenfluramine in obesity. $\mathcal{F}$ R Coll Gen Pract 1977;27:497-501.

(Accepted 20 fuly 1981)

\title{
Antibiotic use in otitis media: patient simulations as an aid to audit
}

\author{
D MARK CHAPUT DE SAINTONGE, N R HATHAWAY
}

\begin{abstract}
Diagnostic and prescribing practices in otitis media vary, and audit is difficult because doctors may not see comparable cases. Seven general practitioners took part in a pilot study to discover if simulated patients evoked the same diagnostic and treatment responses as real patients. Forty-eight patients entered the study over three weeks and provided data for two simulations; one included the doctor's description of the ear and the other a photograph instead. Each doctor was shown the two sets of simulations and asked to state his diagnosis and treatment. The diagnoses each doctor reached agreed significantly with those reached on the simulations of the same patients. The decisions to prescribe antibiotics also showed good agreement.
\end{abstract}

\footnotetext{
Departments of Clinical Pharmacology and Therapeutics, St Bartholomew's Hospital Medical School and London Hospital Medical School, London E1 2AD

D MARK CHAPUT DE SAINTONGE, PHD, MRCP, senior lecturer

Department of Medical Electronics, St Bartholomew's Hospital, London EC1A 7BE

N R HATHAWAY, BS, medical statistician
}

Doctors' judgments on the simulations of each other's patients, however, were significantly different, and five or six cases could be identified as the cause of the disagreement.

This method of comparing clinical judgments is simple and standardised, and it could be used for peer review or self-assessment.

\section{Introduction}

Doctors differ widely in their antibiotic prescribing practices. ${ }^{1}$ In otitis media, for example, anything from $25 \%^{2}$ to $90 \%{ }^{3}$ of cases are given antibiotics. Uncertainty about the diagnosis and lack of agreement on the important prognostic features makes audit difficult. Differences in choice, frequency, and cost of antibiotic prescribing between doctors might reflect only differences in the patients treated; even within a single practice partners see different sorts of patients and uniformity of prescribing might be quite inappropriate. Peer review of individual cases may solve this problem but is almost invariably retrospective and requires access to all the relevant patient data; few patient records are, or will ever be, adequate in this respect. It is impractical for each of a group of doctors to see the same patients, though they could then compare decisions made on the same clinical data. This pilot study examines the related but simpler solution of using patient simulations. 


\section{Methods and results}

The seven doctors taking part in the study were all principals in general practice who had been qualified for from seven to 22 years; four were members of the college of general practitioners. They were asked to refer all children with painful ears seen during a three-week period. The history and physical signs were recorded using a proforma list, and the appearance of the ear drum was noted. The doctors were then asked to record any additional symptoms and signs and social or personal factors that influenced their diagnosis or management. The ear drum was then photographed using a Stortz $4 \mathrm{~mm}$ or $2 \mathrm{~mm}$ teleotoscope and camera; this was accomplished within 10 minutes of the doctor's examination in $90 \%$ of cases. The doctor then estimated the relative probability of the following diagnoses: bacterial otitis media, serous otitis media, mucous otitis media, nonbacterial otitis media, other ear disease, or no ear disease; these diagnostic labels had been chosen by the study doctors before the start of the experiment. He then said what treatment he had prescribed.

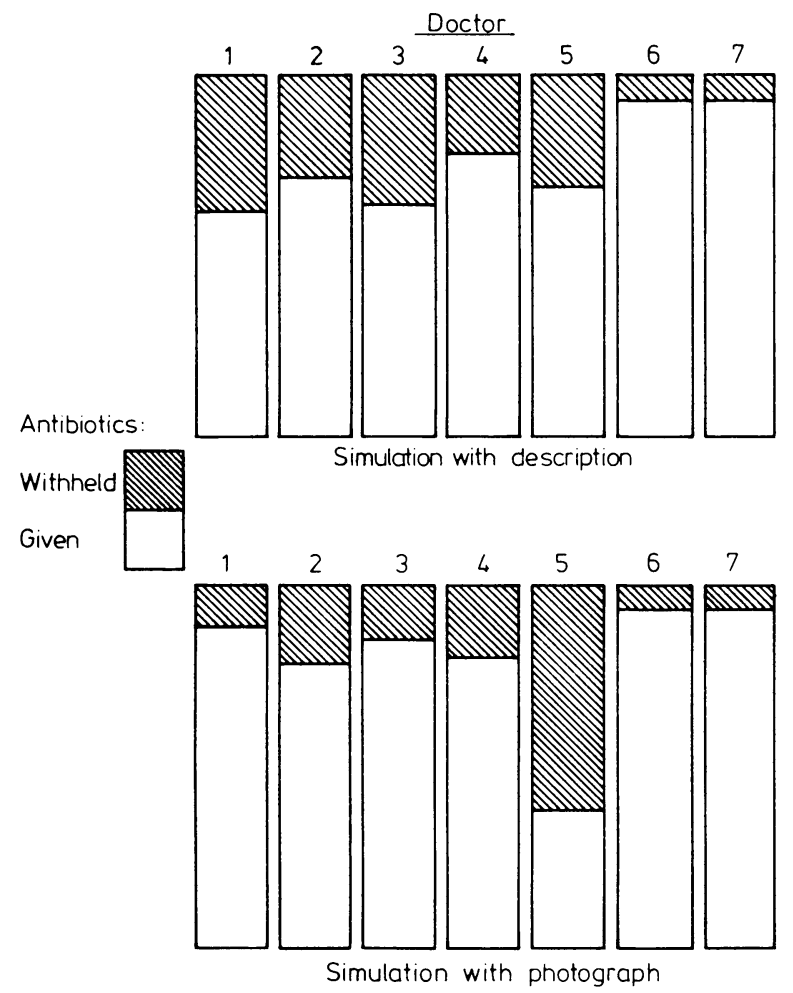

Treatment chosen by each of seven doctors in response to patient simulations.

Forty-eight patients entered the study, but satisfactory photographs were obtained in only 41 cases. Two sets of patient simulations were then prepared: one set consisting of a form containing all the data gathered by the doctor together with his description of the ear drum (total 48); the other set comprising the form and a photograph (total 41). Each of the participating doctors was separately shown the two sets of simulations totalling 89 "patients," and asked to state the diagnosis and treatment. The patients' identities were concealed. Agreement between the diagnosis reached in life and that made by the same doctor in response to the two simulations was examined using Cohen's weighted kappa statistic. ${ }^{4}$ This reckoned the seriousness of disagreements being in proportion to the difference in probability. Thus a probability of otitis media equal to $80 \%$ in real life and $40 \%$ on a simulation represents a disagreement which is twice as serious as one in which the doctor attributes a $60^{\circ}$ \% probability to the simulation.

Two per cent of the simulations could not be analysed. The results showed significant agreement $(p<0.05)$ between the diagnoses reached in life and those reached in both simulations (with description and with photograph). The decisions to use an antibiotic likewise showed good agreement. Although the description seemed to give slightly better agreement than the photograph, the differences were not significant. When doctors' responses to each other's patients are compared on the simulations with description, it is clear from the figure that doctors 6 and 7 tended to prescribe antibiotics more often than any of the others and significantly more so than doctors 1 , 2,3 , and 5 . This was reflected in a high level of disagreement with their policies. Although no doctor changed his pattern of behaviour significantly when shown the photographs, there was a general trend towards prescribing antibiotics more often. The exception is doctor 5 who prescribed less often than he did before and significantly less often than doctors $1,3,6$, or 7 .

\section{Discussion}

The analysis of doctors' prescribing using simulations is not new $^{5}$ and is capable of more sophisticated treatment than we have described-for example, the contribution made to the diagnosis and treatment by each symptom, sign, or social variable can be separated. ${ }^{6}$ In most cases, however, the use of such simulations has remained unvalidated. This small study supports the use of patient simulations to examine prescribing behaviour in otitis media. We have shown that written information evokes diagnostic and therapeutic responses similar to those shown in real life. The use of these patient simulations revealed significant differences between the prescribing behaviour of different general practitioners, which will be reported in more detail elsewhere. Five patients were identified as causing most disagreement and could form a useful focus of discussion for a peer review group. When a photograph was substituted for the written description of the ear drum one doctor showed a surprising change of policy; again, five or six identifiable cases were responsible. The reasons for this change in behaviour are not clear.

It is surprising that the photograph seemed to add little to the description. The photographs offer only a two-dimensional image and may, therefore, have reduced the observers' ability to notice bulging of the drum, making them judge otitis media less likely. Conversely, difficulty in standardising the exposure might result in some drums appearing redder than they were, increasing the chances of otitis media being diagnosed. Inspection of the data provided no support for either possibility, though stereoscopic pictures and improved exposure control methods would reduce the variance attributable to these sources. ${ }^{7}$ Some photographs were of poorer quality than others, and this is another source of variance. It is possible that only a few good photographs could cover the necessary range of ear drum appearances.

The method described can never offer objective validation of judgments since outcome was not measured. It does, however, offer a simple method of comparing diagnostic and therapeutic behaviour under standardised conditions and could form the basis of a system of peer review or self-assessment.

We gratefully acknowledge the generous assistance of the Children's Research Fund and the help of the general practitioners who contributed the data to this study.

\section{References}

${ }^{1}$ Howie JGR, Hutchinson KR. Antibiotics and respiratory illness in general practice: prescribing policy and workload. $\mathrm{Br} M e d \mathcal{F}_{1978}$;ii: 1342.

2 Fry J, Dillane JB, McNab Jones RF, Kalton G. The outcome of acute otitis media. Br F Prev Soc Med 1969;23:205-9.

3 The Medical Research Council's Working Party for Research in General Practice. Acute otitis media in general practice. Lancet 1957;ii:510-4.

4 Cohen J. Weighted kappa: nominal scale agreement with provision for scaled disagreement or partial credit. Psychol Bull 1968;70:213-20.

${ }^{5}$ Howie JGR. Clinical judgement and antibiotic use in general practice. $\mathrm{Br}$ Med F 1976;ii:1061-4.

6 Joyce CRB, Berry H, Chaput de Saintonge M, et al. Judgement analysis of investigators' assessments : a way to reduce one important source of error in multi-centre trials. Eular Bulletin, 1977.

${ }^{7}$ Bain DJG, Morton RA. Photographing the inflamed ear drum in children. Update $1981 ; 23: 171-9$.

(Accepted 7 fuly 1981) 